\title{
A Cross Sectional Study of Cardiopulmonary Complications and Severity of Pulmonary Hypertension and Lung Fibrosis in Patients With Systemic Sclerosis
}

\author{
Wan Ahmad Syahril Rozli WAN ALI, ${ }^{1}$ Mohd Shahrir MOHAMED SAID, ${ }^{1}$ Syahrul Sazliyana SHAHARIR, \\ Andrea Yu Lin BAN, ${ }^{1}$ Rizuana Iqbal HUSSAIN, ${ }^{2}$ Azmillah ROSMAN ${ }^{3}$ \\ ${ }^{1}$ Department of Medicine, University Kebangsaan Malaysia, Kuala Lumpur, Malaysia \\ ${ }^{2}$ Department of Radiology, University Kebangsaan Malaysia, Kuala Lumpur, Malaysia \\ ${ }^{3}$ Department of Medicine, Hospital Selayang, Kuala Lumpur, Malaysia
}

\begin{abstract}
Objectives: This study aims to identify the characteristics of scleroderma patients in terms of sociodemographic and clinical characteristics and severity of lung fibrosis and pulmonary hypertension and to show the association between European Scleroderma Study Group (EScSG) scoring and severity of pulmonary hypertension and lung fibrosis.

Patients and methods: This two center cross-sectional study included 43 scleroderma patients ( 4 males, 39 females; mean age 52 years; range 42 to 59 years) under clinical follow-up. Patients' sociodemographic data were recorded. Median duration of illness was 10.0 years. All patients underwent blood tests, echocardiogram, full lung function test, six-minute walking test, and high resolution computed tomography of the thorax. Pulmonary hypertension was defined by echocardiogram as systolic pulmonary pressure $>36 \mathrm{mmHg}$.

Results: Limited systemic sclerosis was the predominant type (74.7\%). Majority of high resolution computed tomography findings showed lung fibrosis with ground glass opacities (74.4\%). Pulmonary hypertension was predominantly mild (31.7\%), lung function test showed $36.1 \%$ restrictive lung disease, and a reduced diffusing capacity of the lungs for carbon monoxide (median 13.85) with reduced six-minute walking test distance (median 300.0 meters). Health Assessment Questionnaire scoring was predominantly in the mild to moderate disability group (median score of 0.5 ). Five patients (13.9\%) had active disease based on the EScSG scoring. There were no significant associations between EScSG scoring and other clinical parameters.

Conclusion: In our study, we found that scleroderma was predominant among females and the major type was limited systemic sclerosis. The lung function test revealed a sub-normal diffusing carbon monoxide with a reduced six-minute walking distance.

Keywords: Cardiopulmonary complications; disease activity; scleroderma.
\end{abstract}

Systemic sclerosis (SSc) is a rare disorder with diverse manifestations, which usually presents with tightening and sclerosis of the skin. The manifestation ranges from localized to systemic manifestations, with different organ involvement, severity and prognosis. It is related with the presence of widespread tissue fibrosis. Among the important pathogenesis in the development of systemic sclerosis are immune activation leading to vascular damage, and excessive synthesis of extracellular matrix with deposition of increased amounts of structurally normal collagen in the tissues. ${ }^{1}$ These events will hypothetically lead to the generation of a population of activated fibrogenic fibroblasts generally considered to be the effector cell in the disease. ${ }^{2}$

The prevalence rate for SSc varies, ranging from 4 to 489 cases per million individuals, with regional differences in incidence. ${ }^{3-5} \mathrm{~A}$ study 
by Chiflot et.al., ${ }^{6}$ who reviewed 32 articles published from 1969 to 2006, found that the prevalence of $\mathrm{SSc}$ ranged from $7 /$ million to $489 /$ million and its incidence from $0.6 /$ million $/ y$ to $122 /$ million/y. SSc prevalence was higher in the USA (276/million in 1990) and Australia (233/million in 1999) than in Japan and Europe. A north-south gradient was also observed (France: 158/million in 2001 and England: 88/million in 2000). There was also spatiotemporal clustering in some regions (Ontario, Rome, near London's airports), with an unusually high number of SSc cases from 3, 5, or even 1000 times greater than expected. ${ }^{6}$

\section{PATIENTS AND METHODS}

This cross sectional study included 43 scleroderma patients (4 males, 39 females; mean age 52 years; range 42 to 59 years) who were on follow-up in Rheumatology clinic in Pusat Perubatan UKM Medical Centre and Hospital Selayang. Recruitment started from January $1^{\text {st }}$ 2009 till May 31 ${ }^{\text {st }} 2009$. Inclusion criteria were (i) patients aged 18 and above who fulfilled the diagnosis of scleroderma based on American College of Rheumatology/European League Against Rheumatism diagnosis criteria for scleroderma ${ }^{7}$ and (ii) patients with a diagnosis of overlap syndrome with predominant scleroderma features. Patients who did not fulfill the diagnosis of scleroderma, who were aged below 18 years, and who were pregnant were excluded. Informed consents were obtained from all patients. The study was approved by the Research and Ethics Committee of the Faculty of Medicine, University Kebangsaan Malaysia, with the project code of FF-327-2009.

Patients' demographic data and previous autoantibody screening as well as blood investigations were documented. The Health assessment questionnaire (HAQ) disability index was used to assess physical functioning in eight domains (dressing and grooming, arising, eating, walking, hygiene, reach, grip, and other activities). The HAQ-disability index was calculated by summing the highest score in each of the eight domains and dividing the sum by 8 , giving a score between 0 and 3 on a continuous scale. Total scores of 0 to 1 represent mild to moderate disability, 1 to 2 represent moderate to severe disability, and 2 to 3 indicate severe to very severe disability. The validated Malay version of the HAQ-disability index were used for Malay patients. ${ }^{8}$

Clinical assessments were performed for six-minute walking test (6MWT) and modified Rodnan skin score. In the 6MWT, patients were required to walk on a flat, hard surface in a period of six minutes and the distance covered within that particular period were measured. The modified Rodnan skin score was based on a three point scale at specified areas on the body. The score measured skin thickening by palpation of the skin in 17 areas of the body (fingers, hands, forearms, arms, feet, legs, thighs, face, chest, and abdomen) and was scored on a scale of $0-3$, where 0 is normal (no thickening), 1 represents mild thickening, 2 represents moderate thickening, and 3 indicates severe thickening. The total skin score can range from 0 (no thickening) to 51 (severe thickening in all 17 areas). Patients' functional capacity was also assessed by the Borg scale.

The Borg scale was defined as follows: (score of 1 to 10 )

"1" - Exercise is "very light" like walking slowly at your own pace for several minutes.

" 3 " - Exercise is not especially hard; it feels fine and it is no problem to continue.

"5" - Patient is tired, but not having great difficulties.

"7" - The patient can go on, but has to push very much and is very tired.

"10" - The exercise is as hard as most people have ever experienced.

Pulmonary function test was done using the Master Screen Body, Jaeger of Germany by three senior technicians. Parameters included in the test were forced expiratory volume in one second $\left(\mathrm{FEV}_{1}\right)$, forced vital capacity $(\mathrm{FVC}), \mathrm{FEV}_{1} / \mathrm{FVC}$ ratio, peak expiratory flow rate, residual volume, total lung capacity, transfer factor of the lung for carbon monoxide (DLCO) and DLCO divided by alveolar volume.

The patients were then divided into four groups, which were defined as: ${ }^{9}$ group 0 (normal, defined by $\mathrm{FEV}_{1} / \mathrm{FVC}$ ratio of 70 to $75 \%$, normal 
total lung capacity), group 1 (restrictive, defined by decreased total lung capacity of more than fifth percentile, $\mathrm{FVC}$, and $\mathrm{FEV}_{1}$ with a normal or increased $\mathrm{FEV}_{1} / \mathrm{FVC}$ ratio above $75 \%$ ), group 2 (obstructive, defined by a low $\mathrm{FEV}_{1} / \mathrm{FVC}$ ratio less than $70 \%$ or increased residual volume of more than 100), group 3 (mixed, defined by presence of both restrictive and obstructive features).

Echocardiographic studies were performed using commercially available system of Vivid-e, from General Electric (General Electric Healthcare) with 2.5 and $3.5 \mathrm{MHz}$ transducers by an experienced echocardiographer who had no previous knowledge of the patients. Systolic pulmonary artery pressure findings were separated into three groups, namely, mild $(36-45 \mathrm{mmHg})$, moderate $(46-55 \mathrm{mmHg})$, and severe pulmonary hypertension (higher than $56 \mathrm{mmHg}$ ).

High resolution computed tomography (HRCT) scan of the thorax at the end of inspiratory effort with the patient in the supine position and without intravenous contrast were done on all patients after recruitment. HRCT scan results were interpreted independently by radiologists in the absence of information on disease severity and activity.

In a large sample systemic sclerosis study by Steen and Medsger, ${ }^{10}$ the rate of cardiopulmonary complications in systemic sclerosis was about $15 \%$. The sample size was calculated with the help of a statistician using statistical software for population using the formula below:

Sample size estimated by using a formula

$$
\frac{\mathrm{n}=(1.96)^{2} \times \mathrm{p} \times \mathrm{q}}{\mathrm{d}^{2}}
$$

Estimating a population proportion with specified absolute precision

$$
\begin{aligned}
& \text { Anticipated population proportion }(\mathrm{p})=15 \% \\
& \text { Confidence level } \\
& \text { Absolute precision }(\mathrm{d}) \\
& \qquad \begin{array}{cc}
\mathrm{p}=0.15 & =10 \% \\
\mathrm{q}=1-\mathrm{p}=1-0.10 & \mathrm{~d}=0.10 \\
\mathrm{n}=(1.96)^{2} \times \mathrm{p} \times \mathrm{q} & \\
\mathrm{d} 2 & \\
=48 \text { patients }
\end{array}
\end{aligned}
$$

Patients were assessed with the EScSG disease activity scoring, which consisted of 10 variables with weights ranging from 0.5 to 2.0 and resulting in a total score ranging from 0 to 10 . The disease was considered active if the sum of the scores of detected items was $\geq 3$ (Table 1 ).

\section{Statistical analysis}

Statistical analysis was performed using PASW version 17.0 software (SPSS Inc., Chicago, IL, USA). All the data was tested using the Shapiro-Wilk test for normality. The data were nonparametric. Therefore, the data were described in median and interquartile range. Correlation was tested using Spearman's test.

\section{RESULTS}

The baseline and sociodemographic characteristics of the patients are shown in Table 2. Table 3 summarizes the clinical demographics of the patients. HRCT was performed in 39 patients with normal results in two patients. Table 4 summarizes the frequencies of the HRCT scan findings. Based on the echocardiographic findings, patients were further classified into two groups with or without pulmonary hypertension (Table 5). Table 6 shows lung function results of the patients $(n=36)$. Other parameters including modified Rodnan skin score, 6MWT, Borg, HAQ-disability index, pain, and health scores are depicted in Table 7.

Table 1. European Scleroderma Study Group disease activity scoring

\begin{tabular}{lc}
\hline Criteria & Whole series \\
\hline Modified Rodnan skin score $>14$ & 1.0 \\
Scleroderma & 0.5 \\
$\Delta$ Skin & 2.0 \\
Digital necrosis & 0.5 \\
$\Delta$ Vascular & 0.5 \\
Arthritis & 0.5 \\
$\Delta$ Articular/muscular & \\
$\downarrow$ DLCO & 0.5 \\
$\Delta$ Cardiopulmonary & 2.0 \\
ESR $>30$ mm/1 ${ }^{\text {st }} \mathrm{h}$ & 1.5 \\
Hypocomplementemia (C3 and/or C4) & 1.0 \\
Total maximum disease activity index & \\
\hline DLCO: Transfer factor of the lung for carbon monoxide; ESR: Erythrocyte \\
sedimentation rate.
\end{tabular}


Table 2. Baseline characteristics of study patients $(n=43)$

\begin{tabular}{lcccc}
\hline Characteristics & $\mathrm{n}$ & $\%$ & Median & Interquartile range \\
\hline Study center & 32 & 74.4 & & \\
$\quad$ Pusat Perubatan UKM & 11 & 25.6 & & \\
$\quad$ Hospital Selayang & & & 52.0 & $42.0-59.0$ \\
Age (year) & 4 & 9.3 & & \\
Gender & 39 & 90.7 & & \\
$\quad$ Male & 19 & 44.2 & & \\
$\quad$ Female & 18 & 41.9 & & \\
Ethnic & 6 & 14.0 & & \\
$\quad$ Malay & 0 & 0 & & \\
$\quad$ Chinese & & & 10.0 & $30.0-15.0$ \\
$\quad$ Indian & & & & \\
$\quad$ Others & 1 & 2.3 & & \\
Duration of illness (years) & & & & \\
Age of disease onset & & & & \\
Family history of CTD & & & & \\
\hline CTD: Connective tissue disease. & & & & \\
\end{tabular}

Based on the EScSG score, five patients (13.9\%) who scored higher than 3.0 had active disease while 31 patients $(86.1 \%)$ had inactive disease. There was no significant association between EScSG score and other clinical parameters such as types of scleroderma, pulmonary artery pressure, HAQ score, 6MWT, and areas of lung fibrosis ( $p>0.05)$.

When Spearman's correlation coefficient was used, there was a significant negative correlation between pulmonary artery pressure and FVC best/predicted $(\mathrm{r}=-0.346, \mathrm{p}=0.042)$.

Table 3. Clinical demography

\begin{tabular}{|c|c|c|c|}
\hline & $\mathrm{n}$ & $\%$ & Interquartile range \\
\hline \multicolumn{4}{|l|}{ Types of systemic sclerosis } \\
\hline Limited systemic sclerosis & 32 & 74.7 & \\
\hline CREST & 4 & & \\
\hline Diffuse systemic sclerosis & 11 & 25.3 & \\
\hline \multicolumn{4}{|l|}{ Connective tissue subtypes } \\
\hline Overlap syndrome & 25 & 58.1 & \\
\hline Systemic sclerosis & 18 & 41.8 & \\
\hline Systemic sclerosis and rheumatoid arthritis & 13 & & \\
\hline Systemic sclerosis and systemic lupus erythematosus & 11 & & \\
\hline Systemic sclerosis, rheumatoid arthritis and systemic lupus erythematosus & 1 & & \\
\hline \multicolumn{4}{|l|}{ Serology } \\
\hline Antinuclear antibody positive & 28 & 65.1 & \\
\hline Anti ScL-70 & 9 & 33.3 & \\
\hline \multicolumn{4}{|l|}{ Inflammatory markers } \\
\hline Erythrocyte sedimentation rate & 49 & & $22.0-74.0$ \\
\hline \multicolumn{4}{|l|}{ Physical examination } \\
\hline Sclerodactyly & 42 & 97.7 & \\
\hline Microstomia & 40 & 93.0 & \\
\hline Raynaud's phenomenon & 30 & 69.8 & \\
\hline Digital necrosis & 22 & 51.2 & \\
\hline \multicolumn{4}{|l|}{ Medications } \\
\hline Calcium channel blocker & 27 & 62.8 & \\
\hline Prednisolone & 22 & 51.2 & \\
\hline Angiotensin converting enzyme inhibitor & 9 & 20.9 & \\
\hline Angiotensin receptor blockade & 6 & 14 & \\
\hline Penicillamine & 5 & 11.6 & \\
\hline Methotrexate & 1 & 2.3 & \\
\hline Psoralen combined with ultraviolet A & 2 & 4.7 & \\
\hline
\end{tabular}


Table 4. Frequency of high resolution computed tomography scan findings $(n=39)$

\begin{tabular}{lcc}
\hline Characteristics & $\mathrm{n}$ & $\%$ \\
\hline Lung fibrosis & 37 & 86.0 \\
Ground glass opacities & 11 & 25.6 \\
Bronchiectasis & 11 & 25.6 \\
Honeycombing & 10 & 23.3 \\
Bronchovascular thickening & 10 & 23.3 \\
Nodules & 9 & 20.9 \\
Air space consolidation & 5 & 11.6 \\
Mosaic perfusion & 1 & 2.3 \\
High resolution computed tomography scan was not done in four patients. \\
One patient may have more than one abnormality; therefore, total number \\
of abnormalities was different from total number of patients. \\
\hline
\end{tabular}

Expectedly, there was a significant negative correlation between Borg score and 6MWT distance $(\mathrm{r}=-0.821, \mathrm{p}<0.001)$.

There was a significant correlation between $\mathrm{FEV}_{1} / \mathrm{FVC}(\%)$ and EScSG and HAQ scores. A significant but weak correlation was found between DLCO divided by alveolar volume and HAQ score ( $r=-0.347, p=0.045)$. Pain and health scores also had a significant correlation with HAQ score. The Rodnan skin score was strongly correlated with HAQ $(r=0.671, p \leq 0.001)$. There was no significant correlation between lung function and duration of illness $(r=0.122, p=0.478)$.

\section{DISCUSSION}

In general, scleroderma affects primarily the female sex. This was also the same in our study, with 39 female patients (90.7\%). The predominance of females has also been reported in two large, national cohorts of scleroderma in France and Germany. ${ }^{11,12}$ The rate of female patients in both cohorts was $83.8 \%$, with $5: 1$
Table 5. Severity of pulmonary hypertension $(n=42)$

\begin{tabular}{lcc}
\hline Characteristics & $\mathrm{n}$ & $\%$ \\
\hline No pulmonary hypertension & 21 & 50.0 \\
Mild pulmonary hypertension & 13 & 31.0 \\
Moderate pulmonary hypertension & 5 & 11.9 \\
Severe pulmonary hypertension & 3 & 7.0 \\
\hline
\end{tabular}

ratio. Similar findings have been reported in two local retrospective studies by Pagalavan and Ong $^{13}$ and Teh et. al. ${ }^{14}$ from Hospital Kuching. The median age of disease onset (39 years) in our study slightly differed from the onset described by previous studies. Hence, mean ages of onset were approximately 48 years and 44 years in two cohort studies by Hachulla et al. ${ }^{12}$ and Hunzelmann et al., ${ }^{11}$ respectively. The durations of disease were wide-ranging in our study, extending from three to 25 years.

Most of the patients (67.4\%) were unemployed due to their disease and limitation in working. The predominance of limited scleroderma was evident in this study, as shown in previous large cohort studies from France and Germany.11,12 As with other previous studies, we observed that patients with diffuse scleroderma have more organ complications with poorer functional status. ${ }^{15}$

An analysis of patients' treatments in this study revealed that the majority of patients were on calcium channel blockers and steroids, while no patient received cyclophosphamide, prostanoids or cyclosporin A. Based on our observation, these medications were not started because almost all of the patients presented with progressed disease with already established lung fibrosis and recurrent lung infections. In a double-blind, randomized, placebo-controlled trial by Tashkin et al., ${ }^{16}$ cyclophosphamide has been shown to

Table 6. Lung function results $(n=36)$

\begin{tabular}{lcc}
\hline Lung function parameters & Median & Interquartile range \\
\hline Forced expiratory volume in one second (L) & 1.44 & $1.19-1.73$ \\
Forced vital capacity (L) & 1.83 & $1.44-2.09$ \\
Forced expiratory volume in one second (best/predicted \%) & 68.80 & $53.58-83.20$ \\
Forced vital capacity (best/predicted \%) & 70.50 & $53.60-83.20$ \\
Forced expiratory volume in one second/forced vital capacity & 64.30 & $78.03-86.60$ \\
Peak expiratory flow rate (best/predicted \%) & 104.00 & $45.3-95.3$ \\
Residual volume (best/predicted \%) & 80.90 & $67.8-130.9$ \\
Total lung capacity (best/predicted \%) & $13.85 \mathrm{mmol} / \mathrm{min} / \mathrm{kPa}$ & $62.50-90.50$ \\
Transfer factor of the lung for carbon monoxide & $3.89-23.00$ \\
Transfer factor of the lung for carbon monoxide divided by alveolar volume & $32.50 \mathrm{mmol} / \mathrm{min} / \mathrm{kPa} / \mathrm{L}$ & $22.75-45.00$ \\
\hline
\end{tabular}


Table 7. Other parameters $(n=43)$

\begin{tabular}{lcc}
\hline Parameters & Median & Interquartile range \\
\hline Modified Rodnan skin score & 20.0 & $15.0-27.0$ \\
6 minute walking test distance & 0 & $258.5-337.5$ \\
Borg score & 2.00 & $1.25-3.00$ \\
Health assessment questionnaire disability index score & 0.50 & $0.25-0.87$ \\
Pain score & 20.00 & $20.0-30.0$ \\
Health score & 30.00 & $25.0-40.0$ \\
\hline
\end{tabular}

improve interstitial lung disease in scleroderma. The current accepted treatment for pulmonary hypertension includes using bosentan which is a dual-endothelin receptor antagonist. Bosentan's effects were shown in a double-blind, placebo controlled trial by Rubin et al. ${ }^{17}$ and its long-term effects were studied by Denton et al., ${ }^{18}$ which also showed similar findings.

The most frequent pathological lung changes in this study were lung fibrosis (86.0\%), followed by ground glass opacities and bronchiectatic changes (25.6\%). These changes were also compatible with the Scleroderma Lung Study and non-specific interstitial pneumonia pattern reported in previous studies by Ooi et al. ${ }^{19}$ and Fujita et al. ${ }^{20}$ Systemic sclerosis with rheumatoid arthritis group may also predispose the patients to have lung changes, as rheumatoid arthritis itself is associated with interstitial lung disease as reported by Mohd Noor. ${ }^{21}$ and also in a number of other studies. ${ }^{22,23}$ It was also interesting to note in our study that pathological changes were present in HRCT scans of 12 patients (27.9\%) without cardiorespiratory symptoms.

The subset of full lung function test in this study was only performed in 36 patients since, among the 43 recruited patients, seven were bedbound and severely debilitated, and unable to perform the full lung function test and the $6 \mathrm{MWT}$. Of the 36 patients, the majority had normal results while 13 patients (36.1\%) had restrictive pattern. The percentage of restrictive pattern was lower in this study than described by Spagnolatti et al. ${ }^{24}$ and an older study by Owens et al. ${ }^{25}$ (41\% and 28\%, respectively). In our patients, the low percentage (8.3\%) of obstructive pattern may be related to the possibility of underlying undiagnosed obstructive lung disease. Both the median DLCO and FVC were low in our study, compared to previous studies where Hoyles et al. ${ }^{26}$ reported a baseline
FVC of $82 \%$ and DLCO of 55\%, and Hachulla et al. ${ }^{12}$ reported a baseline DLCO of 56.2 to $72.6 \%$ predicted. This finding is directly related to the ability and the blowing technique of the patients. We observed that the low rates of DLCO and FVC in this study were due to the poor blowing ability of the patients, particularly in the group with more severe pulmonary involvement.

One of the main objectives of this study was to measure disease activity based on the $\mathrm{EScSG}$ scoring system. The majority of the patients had inactive disease based on the EScSG score measurement. Only five patients (13.9\%) scored 3 and above, falling into the category of active disease. Most of these patients had high Rodnan skin scores, with reduced DLCO and high erythrocyte sedimentation rate. One patient had described a change in cardiopulmonary symptoms one month before. Based on Spearman's test, there was a significant correlation between disease activity and $\mathrm{FEV}_{1} / \mathrm{FVC}$ percentage $(\mathrm{r}=346, \mathrm{p}=0.042)$.

In the 6MWT, we used 300 meters as the cutoff distance compared with the study of Villalba et al. ${ }^{27}$ who used 400 meters as the cut-off point. This was due to the slightly limited capabilities of our patients, of which only four (11.1\%) out of 36 were able to walk beyond that distance. The median of distance in our study was also lower which was 300.0 meters, compared to the study of Villalba et al. ${ }^{27}$ with a distance of 450 meters. Based on the 300 meters cut-off point, 16 patients (37.2\%) were able to walk less than 300 meters, and 20 patients $(55.6 \%)$ were able to walk more than 300 meters.

Although HAQ was initially developed for usage in rheumatoid arthritis, it has proven to be a useful assessment in a number of scleroderma studies, including the Scleroderma Lung Study. ${ }^{15,28,29}$ In our study, the median HAQ score was 0.50 (interquartile range 0.25-0.87). 
Most of the patients (79.1\%) had mild to moderate disability, which was different compared to the study of Clements et al., ${ }^{30}$ who reported a mean baseline score of $1.04 \pm 0.67$, which correlates with moderate to severe disability. We demonstrated a significant correlation between HAQ and $\mathrm{FEV}_{1} / \mathrm{FVC}(\%)(\mathrm{r}=0.439, \mathrm{p}=0.007)$, and also between HAQ and DLCO divided by alveolar volume $(r=-0.347, p=0.045)$. In our study, the HAQ was also significantly correlated with pain, health, and total Rodnan skin scores. However, this was an expected finding since the factors mentioned were usually impaired when there is impaired functional status. For example, the higher the Rodnan skin score, the more severe disability the patients will have. The significant positive correlation of $\mathrm{FEV}_{1} / \mathrm{FVC}$, on the other hand, cannot be clearly explained, unless if the higher $\mathrm{FEV}_{1} / \mathrm{FVC}$ translates into a more severe restrictive lung disease.

In conclusion, the majority of systemic sclerosis patients in our center was females, with an approximate onset age of 39 years. Almost all of the patients had lung fibrosis, with almost half having non-specific interstitial pneumonia pattern in HRCT. Most of the patients were stable. The patients also had normal to mild pulmonary hypertension, with under-averaged lung function test, especially in the DLCO and FVC readings. Furthermore, the cut-off and average 6MWT distances were significantly lower in our study. As with other studies, there was a significant correlation between FVC and pulmonary artery pressure.

\section{Acknowledgement}

We would like to thank the Dean and Director of Hospital Chanselor Tuanku Mukhriz, Prof. Dato' Dr. Raymond Azman Ali, and the Head of Medical Department Hospital Selayang, Dr. Azmillah Rosman, for their valuable cooperation in this study.

\section{Declaration of conflicting interests}

The authors declared no conflicts of interest with respect to the authorship and/or publication of this article.

\section{Funding}

The authors received no financial support for the research and/or authorship of this article.

\section{REFERENCES}

1. Systemic sclerosis: current pathogenetic concepts and future prospects for targeted therapy. Lancet 1996;347:1453-8.

2. Piela-Smith TH, Korn JH. Lymphocyte modulation of fibroblast function in systemic sclerosis. Clin Dermatol 1994;12:369-77.

3. Geirsson AJ, Steinsson K, Guthmundsson S, Sigurthsson V. Systemic sclerosis in Iceland. A nationwide epidemiological study. Ann Rheum Dis 1994;53:502-5.

4. Hatano H. Epidemiology of connective tissue diseases of the skin (scleroderma, dermatomyositis and polymyositis) in Japan. HautarzT 1982;33:355-8. [Abstract]

5. Medsger TA Jr. Epidemiology of systemic sclerosis. Clin Dermatol 1994;12:207-16.

6. Chifflot H, Fautrel B, Sordet C, Chatelus E, Sibilia $\mathrm{J}$. Incidence and prevalence of systemic sclerosis: a systematic literature review. Semin Arthritis Rheum 2008;37:223-35.

7. van den Hoogen F, Khanna D, Fransen J, Johnson SR, Baron M, Tyndall A, et al. 2013 classification criteria for systemic sclerosis: an American college of rheumatology/European league against rheumatism collaborative initiative. Ann Rheum Dis 2013;72:1747-55.

8. Hussein H, Mustafa R, Quek KF, Hassanudin NS, Shahid S. Cross-cultural adaptation and validation of the Malay health assessment questionnaire for use in rheumatoid arthritis. Int $J$ Rheum Dis 2008;11:237-40.

9. Lung function testing: selection of reference values and interpretative strategies. American Thoracic Society. Am Rev Respir Dis 1991;144:1202-18.

10. Steen VD, Medsger TA Jr. Severe organ involvement in systemic sclerosis with diffuse scleroderma. Arthritis Rheum 2000;43:2437-44.

11. Hunzelmann N, Genth E, Krieg T, Lehmacher W, Melchers I, Meurer $\mathrm{M}$, et al. The registry of the German Network for Systemic Scleroderma: frequency of disease subsets and patterns of organ involvement. Rheumatology (Oxford) 2008;47:1185-92.

12. Hachulla E, Gressin V, Guillevin L, Carpentier P, Diot E, Sibilia J, et al. Early detection of pulmonary arterial hypertension in systemic sclerosis: a French nationwide prospective multicenter study. Arthritis Rheum 2005;52:3792-800.

13. Pagalavan L, Ong SG. Demography, clinical and laboratory features of systemic sclerosis in a Malaysian rheumatology centre. Med J Malaysia 2007;62:117-21.

14. Teh CL, Kuan YC, Wong JS. Systemic sclerosis in Sarawak: a profile of patients treated in the Sarawak General Hospital. Rheumatol Int 2009;29:1243-5.

15. Morita Y, Muro Y, Sugiura K, Tomita Y, Tamakoshi K. Results of the Health Assessment Questionnaire for 
Japanese patients with systemic sclerosis--measuring functional impairment in systemic sclerosis versus other connective tissue diseases. Clin Exp Rheumatol 2007;25:367-72.

16. Tashkin DP, Elashoff R, Clements PJ, Goldin J, Roth MD, Furst DE, et al. Cyclophosphamide versus placebo in scleroderma lung disease. N Engl J Med 2006;354:2655-66.

17. Rubin LJ, Badesch DB, Barst RJ, Galie N, Black CM, Keogh A, et al. Bosentan therapy for pulmonary arterial hypertension. N Engl J Med 2002;346:896-903.

18. Denton CP, Pope JE, Peter HH, Gabrielli A, Boonstra $\mathrm{A}$, van den Hoogen $\mathrm{FH}$, et al. Long-term effects of bosentan on quality of life, survival, safety and tolerability in pulmonary arterial hypertension related to connective tissue diseases. Ann Rheum Dis 2008;67:1222-8.

19. Ooi GC, Mok MY, Tsang KW, Wong Y, Khong PL, Fung PC, et al. Interstitial lung disease in systemic sclerosis. Acta Radiol 2003;44:258-64.

20. Fujita J, Yoshinouchi T, Ohtsuki Y, Tokuda M, Yang Y, Yamadori I, et al. Non-specific interstitial pneumonia as pulmonary involvement of systemic sclerosis. Ann Rheum Dis 2001;60:281-3.

21. Mohd Noor N, Mohd Shahrir MS, Shahid MS, Abdul Manap R, Shahizon Azura AM, Azhar Shah S. Clinical and high resolution computed tomography characteristics of patients with rheumatoid arthritis lung disease. Int J Rheum Dis 2009;12:136-44.

22. Lee HK, Kim DS, Yoo B, Seo JB, Rho JY, Colby TV, et al. Histopathologic pattern and clinical features of rheumatoid arthritis-associated interstitial lung disease. Chest 2005;127:2019-27.

23. Bongartz T, Nannini C, Medina-Velasquez YF, Achenbach SJ, Crowson CS, Ryu JH, et al. Incidence and mortality of interstitial lung disease in rheumatoid arthritis: a population-based study. Arthritis Rheum 2010;62:1583-91.

24. Spagnolatti L, Zoia MC, Volpini E, Convertino G, Fulgoni P, Corsico A, et al. Pulmonary function in patients with systemic sclerosis. Monaldi Arch Chest Dis $1997 ; 52: 4-8$.

25. Owens GR, Fino GJ, Herbert DL, Steen VD, Medsger TA Jr, Pennock BE, et al. Pulmonary function in progressive systemic sclerosis. Comparison of CREST syndrome variant with diffuse scleroderma. Chest 1983;84:546-50.

26. Hoyles RK, Ellis RW, Wellsbury J, Lees B, Newlands P, Goh NS, et al. A multicenter, prospective, randomized, double-blind, placebo-controlled trial of corticosteroids and intravenous cyclophosphamide followed by oral azathioprine for the treatment of pulmonary fibrosis in scleroderma. Arthritis Rheum 2006;54:3962-70.

27. Villalba WO, Sampaio-Barros PD, Pereira MC, Cerqueira EM, Leme CA Jr, Marques-Neto JF, et al. Six-minute walk test for the evaluation of pulmonary disease severity in scleroderma patients. Chest 2007;131:217-22.

28. Poole JL, Steen VD. The use of the Health Assessment Questionnaire (HAQ) to determine physical disability in systemic sclerosis. Arthritis Care Res 1991;4:27-31.

29. Goldin JG, Lynch DA, Strollo DC, Suh RD, Schraufnagel DE, Clements PJ, et al. High-resolution CT scan findings in patients with symptomatic scleroderma-related interstitial lung disease. Chest 2008;134:358-67.

30. Clements PJ, Wong WK, Hurwitz EL, Furst DE, Mayes $\mathrm{M}$, White $\mathrm{B}$, et al. Correlates of the disability index of the health assessment questionnaire: a measure of functional impairment in systemic sclerosis. Arthritis Rheum 1999;42:2372-80. 